\title{
QUINCE HIPÓTESIS SOBRE GÉNEROS PARA DELATAR AL MICRORRELATO
}

\author{
FIFTEEN HYPOTHESES ON GENRES \\ TO DELATATE THE MICROSTORY
}

Belén MATEOS BLANCO

Universidad de Valladolid mariabelen.mateos@uva.es

\begin{abstract}
Resumen: este trabajo pretende delatar la identidad genérica del microrrelato a partir de los postulados de Alberto Vital en Quince hipótesis sobre géneros (2012). Los axiomas del mexicano se apartan del estudio tradicional que ciñe su análisis a las características discursivas, formales, temáticas y pragmáticas. Vital presenta un método de diagnóstico y evaluación cuyas herramientas tratan de justificar el concepto de género literario de acuerdo con la incidencia y relación de este con el hombre: su historia, su cultura, sus necesidades y momentos vitales, su papel en la sociedad que habita...
\end{abstract}

Palabras clave: microrrelato, género, identidad, hipótesis, Vital.

\begin{abstract}
: this work aims to reveal the generic identity of the microstory from the postulates of Alberto Vital in Fifteen hypotheses on genres (2012). The axioms of the Mexican diverge from the traditional study that confines his analysis to the discursive, formal, thematic and pragmatic characteristics. Vital presents a method of diagnosis and evaluation whose tools try to justify the concept of literary genre according to the incidence and relation of this with man: his history, his culture, his needs and vital moments, his role in the society that inhabits ...
\end{abstract}

Keywords: microstory, gender, identity, hypothesis, Vital. 

iseccionar las relaciones genéricas del microrrelato con otras modalidades textuales —narrativas, didáctico-ensayísticas, periodísticas, poéticas, dramáticas, y con las emergentes fórmulas y soportes literarios enmarcados en el seno de la posmodernidad-, para comprobar, cómo sus rasgos y peculiaridades se desdibujan de acuerdo con su carácter proteico, y, previo análisis de sus características discursivas, formales, temáticas y pragmáticas que avalan las definiciones elaboradas por los especialistas del género, es la metodología habitual cuando la pretensión es dotarlo de autonomía para poder afirmar que el microrrelato es el cuarto género narrativo. Sin embargo, este trabajo pretende delatar la identidad genérica del microrrelato a partir de los postulados de Alberto Vital en Quince hipótesis sobre géneros (2012). Los axiomas del mexicano se presentan como un método de diagnóstico cuyas herramientas tratan de justificar el concepto de género literario de acuerdo con la incidencia y relación de este con el hombre: su historia, su cultura, sus necesidades y momentos vitales, su papel en la sociedad que habita..

El interés de la literatura comparada en la identificación de los géneros literarios reside en la teoría de la recepción puesto que "la riqueza y diversidad de los géneros discursivos es inmensa, porque las posibilidades de la actividad humana son inagotables y porque en cada esfera de la praxis existe todo un repertorio de géneros discursivos que se diferencia y crece a medida que se desarrolla y crece la esfera misma" (Mijaíl Batjín, citado en Vital, 2012: 7). A partir de esta máxima del autor soviético extrapolaremos las quince hipótesis planteadas por Vital a la genética del microrrelato definida por sus teóricos, para concluir con los cinco elementos que necesariamente deben contener la definición de un género.

\section{1. "Los géneros son un puente entre la literatura y la sociedad"}

La necesidad de contar historias es inherente a la condición humana, del mismo modo que la literatura cumple con su función espejo al reflejar el entorno y la colectividad del hombre. "La sociedad contemporánea -la de finales del siglo XIX, la de todo el XX, la que tenemos en lo que va del XXIse ha ido encaminando en forma vertiginosa hacia lo que podemos llamar el discurso de la brevedad" (Lagmanovich, 2009: 89). Las grandes novelas decimonónicas parecen no adaptarse a la trepidante vorágine del mundo contemporáneo, en el que prima lo urgente "sobre el ser humano que naufraga en una sociedad caótica, despersonalizada, marcada por la soledad, la incomunicación, la crueldad, la intolerancia y la injusticia se manifiesta tanto en las minipiezas como en las narraciones microscópicas" (Zavala, 2005: 453).

El microrrelato del siglo XXI, inmerso en la era de la globalización, goza de reconocimiento académico y se ha convertido en todo un fenómeno socioliterario que da "respuesta a esos condicionamientos sociales; ciertos narradores han optado por formas breves o brevísimas: disminuyen 
toda descripción hasta convertirla en insinuación; eliminan las digresiones, evitando cualquier tramo -cualquier desvío- que no implique un avance o progreso en la acción" (Lagmanovich, 2009: 89).

\section{2. "Los géneros no sólo nacen de otros géneros; también nacen de impulsos primarios y requerimientos básicos de la especie"}

El microrrelato nace por lo tanto como un género revulsivo cuyo escepticismo radical cuestiona las verdades absolutas: textos excéntricos, que privilegian los márgenes frente a los centros canónicos de la Modernidad (experimentación con temas, personajes, registros lingüísticos y formatos literarios que habían sido relegados a un segundo plano), mestizaje genérico, importancia del paratexto (títulos, epígrafes, citas...), ruptura de los moldes expresivos..."un importante giro cultural que va de una estética de la permanencia a la que ha sido venerada durante mucho tiempo, y que se basa en la creencia de un ideal de belleza inmutable y trascendente a una estética de la transitoriedad e inmanencia, cuyos valores primordiales son el cambio y la novedad" (Calinescu, 2003: 19).

Respecto a de qué manera incide y se manifiesta la posmodernidad en el texto literario y, en consecuencia, en el microrrelato, Pozuelo Yvancos (2005: 23), cita los cinco rasgos más significativos:

- Heteroglosia y multiplicidad de normas y modelos estéticos: eclecticismo focalizado en la crisis de las narraciones tesis y de las arquitecturas compositivas complejas.

- Fungibilidad y mercado editorial: la literatura sometida, condicionada y reducida, más que nunca, a su condición de objeto de mercado.

- Predominio de la privacidad: proceso de lirismo en el planteamiento egocentrista del propio material narrativo.

- Desconfianza hacia la literariedad: ruptura de la experimentación narrativa y cosmopolitismo ficcional.

- Carácter metaliterario y subrayado de la convención: la autoficción.

Resulta conveniente adaptar y concretar en el género del microrrelato las claves que Pozuelo Yvancos extrae del análisis cualitativo-comparativo de las características de las formas literarias redefinidas en el movimiento posmoderno. Las peculiaridades que definen el estatuto genérico del microrrelato lo postulan como un acicate a medida del posmodernismo: su genética, carácter proteico y fuerte tendencia a la hibridación crean el caldo de cultivo idóneo para el escritor quien se siente libre para cuestionar y romper las estructuras literarias anquilosadas; el autor fagocita la figura del editor al multiplicarse los medios y soportes de difusión favorecidos por las nuevas tecnologías de la comunicación; además estas nuevas plataformas de autopublicación propician la interacción entre diferentes códigos semióticos que generan nexos más allá de lo estrictamente literario. 


\title{
3. "Funciones y marcas, base de la generación de géneros, son una necesidad de la especie que se realiza de manera consuetudinaria en cada persona"
}

A colación de la premisa anterior, la eclosión del microrrelato se ha visto favorecida por el carácter descreído y rupturista del posmodernismo,

\begin{abstract}
[...] un movimiento que se enfrenta en negativo a los grandes valores de la Modernidad: la fe en el progreso (como el mejor camino para transformar el mundo al servicio del ser humano), la afirmación de la identidad individual, la importancia de los grandes discursos legitimadores (en los más diversos ámbitos: filosófico, religioso, político, económico, etc.), la consideración de la realidad como un todo organizado (y, por ende, interrelacionado). (Garrido Domínguez, 2008: 50)
\end{abstract}

La oposición al Modernismo va mucho más allá de la disciplina literaria, que es la fiel representación de los cambios de índole social y del propio individuo; el posmodernismo absorbe todos los elementos característicos de la corriente anterior y los subvierte, ensalzando

[...] la importancia del mundo urbano y de la sociedad de consumo, la exacerbación del individualismo, la globalización (y el neoliberalismo), el multiculturalismo, el rechazo radical del poder establecido, la desmitificación en grado extremo (igualitarismo: todos al mismo nivel), la primacía de lo económico, el hedonismo, la omnipresencia de los media, el auge de la interpretación). (Garrido Domínguez, 2008: 50)

\section{4. "La reflexión sobre géneros literarios se vincula cada vez más con la reflexión sobre géneros no literarios"}

El calado del posmodernismo impregna todos los estratos de la sociedad y también todas las ramas de las disciplinas del arte y las humanidades; el carácter proteico de la minificción favorece la mezcolanza y concomitancia entre códigos, géneros y soportes. Laura Zavala (2014: 33) precisa estas fusiones a las que se presta la minificción literaria y no literaria, además de elaborar una breve y práctica guía con cuestiones analíticas:

No toda minificción es literaria. La letra de una canción, la escena particular que un espectador recuerda después de ver una película o algunas formas de publicidad pueden ser leídas como minificciones, precisamente al reconocer en ellos la presencia de los elementos señalados. Las preguntas que pueden ser formuladas para efectuar el análisis de una minificción (o de un fragmento o fractal textual leído como minificción) son las siguientes:

1. ¿Cuáles son los elementos anafóricos en el inicio y en el empleo del tiempo?

2. ¿Cuál es la dimensión metonímica del espacio?

3. ¿En qué medida los personajes cumplen una función alusiva?

4. ¿Cómo se manifiesta la naturaleza metafórica en el empleo del lenguaje?

5. ¿Cómo ocurre la hibridación o alegorización de las convenciones genéricas?

6. ¿En qué consiste la función catafórica de la intertextualidad y del final?

Zavala propone un análisis sistemático que posibilite el diagnóstico y la identificación de la minificción independientemente de su naturaleza. El profesor mexicano fija en su estudio cuáles son los elementos que permiten resolver su caracterización: principio-final, tiempo, espacio, personajes, lenguaje, género e intertexto. Estos componentes establecen relaciones entre sí, ahora bien, determinar cuándo se produce esta conexión y si lo hace con carácter anterior o posterior a la alusión, verificar si existen cruces entre relaciones semánticas, valorar si la función poética prevalece en el uso del lenguaje 
y, por último, determinar si existen indicios de fusión, mezcolanza o concomitancia genérica constituyen la rúbrica para reconocer minificciones.

\section{5. "Los géneros literarios estarán cada vez más atenidos a las condiciones de los medios masivos} de información y de las redes sociales, así como de las innovaciones tecnológicas"

El microrrelato ha sido etiquetado por expertos y creadores como género posmoderno por antonomasia, pues, a pesar de que puede rastrearse esta modalidad textual desde finales del XIX, el microrrelato adquiere completud en los siglos XX y XXI gracias al desarrollo de la tecnología que abre la vía a nuevos métodos de autopublicación, "donde la imprenta compite con las nuevas tecnologías, abriendo nuevos cauces de creación, difusión y recepción” (Zavala, 2005: 460).

Los microtextos se adaptan progresivamente al creciente paradigma tecnológico, si primero fueron los blogs y bitácoras especializados, ahora el microrrelato posee su propia revista en red y prolifera rápidamente en redes sociales, generando fenómenos como el de la Twiteeratura:

La consideración del microrrelato como fenómeno cultural, más allá de su normalización como género literario, se encuentra íntimamente ligada a su carácter proteico, que propicia su hipermedialidad, es decir, su adaptabilidad a diversos medios y su presencia en variados soportes tradicionales y, sobre todo, digitales. A estas alturas, nadie puede cuestionarse el impulso que los medios de comunicación de masas y, en especial, las redes creadas gracias a internet, han supuesto para la creación, difusión y recepción del microrrelato. (Bustamante, 2017: 27)

La hipermedialidad mencionada por Leticia Bustamante adquiere la categoría de atributo genérico del microrrelato derivado de su marcada tendencia a la hibridación y como resultado de la revolución tecnológica que facilita su publicación en diversos soportes. En el capítulo titulado "Mecanismos intertextuales y taxonomía tematológica del microrrelato" atenderemos a este tipo de relaciones y a su categorización de acuerdo con los conceptos de intermedialidad interna, intermedialidad externa e intermedialidad mixta.

\section{6. "Existen determinados géneros óptimos para determinadas situaciones de vida"}

De las anteriores hipótesis deducimos que, el microrrelato se ha convertido en una manifestación social y literaria símbolo de la posmodernidad; precisamente, la confluencia de estos dos aspectos, dota a la fase de recepción de especial relevancia, puesto que los recursos de creación y hábitos de consumo lector están actualmente sujetos a unas normas de producción muy diferentes a las del siglo pasado:

Los espacios mínimos constituyen todo un reto para los creadores que sienten que sus obras constituyen el fiel reflejo de una sociedad marcada por el ritmo vertiginoso de la vida cotidiana, por el influjo de los medios de comunicación de masas y por el impacto de las nuevas tecnologías. La minificción se ha erigido en el signo de los nuevos tiempos reclamando nuevos modelos de creación y de recepción, como se desprende sin duda del reto asumido por el corto cinematográfico y el microrrelato literario. (Zavala, 2005: 449) 
La teoría que atribuye el éxito del microrrelato al contexto de la sociedad actual apela a varios de los aspectos ya analizados, como la inmediatez, la fugacidad, la efectividad, al obligado cumplimiento del pacto de lectura y al influjo de las nuevas tecnologías de los medios de comunicación y redes sociales. Es importante extender esta idea a la máxima de calidad que debe cumplir cualquier texto literario y las especiales características que lo definen:

El éxito de un texto narrativo, por ejemplo, un microrrelato, no deriva tan sólo de la correcta elección de los temas, la configuración precisa de los personajes o de la homogeneidad en la estructura elegida. Que un relato goce del favor del lector depende también de elementos de orden discursivo como el lenguaje empleado, la focalización de la historia o el ritmo de la narración. (Pujante Cascales, 2013: 469)

\section{7. "Los géneros son generativos"}

La identificación y catalogación de cualquier texto literario resulta necesaria para favorecer su creación y posterior asentamiento en el mercado editorial. Así pues, la preocupación por definir las particularidades genéticas y los rasgos fundacionales del microrrelato surge de los mismos creadores ante la conciencia de estar enfrentándose a un nuevo modelo de escritura y la necesidad de ubicarlo en el marco de la literatura tradicional:

1) toda persona tiene en principio la posibilidad de elaborar textos literarios si encuentra circunstancias colectivas favorables para géneros adecuados a las posibilidades de cada quien: los géneros son generados bajo condiciones públicas propicias, y 2) una vez establecidas y aceptadas por consenso tácito o explícito las reglas mínimas del correspondiente esquema discursivo o género, el potencial autor siente, aunque sea en mínima medida, el impulso para elaborar un texto bajo las reglas propuestas. (Vital, 2012: 16)

Esta idea adquiere una dimensión especial ceñida al microrrelato, puesto que, este afán por categorizarlo y enmarcarlo en la teoría tradicional de los géneros se convertirá en una de sus temáticas recurrentes, que cristalizará en microtextos metaliterarios los cuales denominaremos archimicrorrelatos.

\section{8. "En ciertos casos es imprescindible rastrear derivaciones de un género literario en disciplinas no literarias"}

Este postulado que es inherente al texto literario desde sus orígenes, se mantiene en la actualidad y fundamenta varias de las características genéricas del microrrelato; desde la materialización escrita de romances y cantares de gesta recitados por los autores del mester de juglaría y del mester de clerecía en la Edad Media; los cuentos de tradición oral recopilados desde finales del XVIII por el romanticismo francés; los folletines decimonónicos de Dickens o Tolstói, o el dadaísmo de Tristán Tzara:

En el siglo XX se desarrolla una profunda transformación en las técnicas narrativas relacionadas con el tratamiento de la secuencia temporal, la ruptura del orden interno de la fábula, los análisis de los distintos estados y estratos de la conciencia y del inconsciente (flujo de conciencia, estados prelógicos, oníricos), el entrecruzamiento de diversos niveles de lenguaje, el uso de técnicas procedentes del cine (yuxtaposiciones, acumulación, narración en paralelo, flash-back, etc.), de la estructura musical”. (Estébanez Calderón, 1999:748) 
Envuelto en el posmodernismo, la minificción, asimila fórmulas de otras disciplinas del ámbito de las humanidades, transformándolas, como por ejemplo el graffiti y el cómic, y creando nuevas identidades narrativas tales como los microrrelatos ilustrados o los hipertextos derivados de su relación con obras pictóricas o cinematográficas:

La brevedad extensional, sintetización expresiva y economía narrativa, la condensación de todos los elementos de la historia narrada, la atención sinecdóquica a lo parcial antes que, a lo total, la enfatización de los mecanismos de tensión e intensidad narrativa, la acentuación de la capacidad de evocación y sugerencia (ligados al poema, la fotografía o la pintura), son caracteres compartidos por el cuento y el microrrelato, pero que aparecen potenciados en este último. (Valles Calatrava, 2008: 54)

\section{9. "Existe una latente división internacional de los géneros"}

Si bien es cierto que la canonización del microrrelato es un hecho, sus rasgos fundacionales y la manera de denominarlo no es la misma en todos los países. La crítica anglosajona se ha ocupado de este aspecto, y en su tradición literaria encontramos varios términos utilizados como sinónimos de minificción: flash, short story, suddenfiction, flash fiction, microfiction, drabble y nanofiction.

En la literatura escrita en español tampoco hay acuerdo en lo que se refiere al término exacto que define un minicuento, una minificción o un microrrelato, "se debe precisar que en distintos ámbitos geográficos y lingüísticos han surgido nomenclaturas diferentes de las que manejamos en el mundo hispánico, [...], el hecho de que en la literatura brasileña se prefiera el término crónica (Noguerol, 1992: 117) o que en China hayan aparecido denominaciones como cuento de bolsillo, cuento de un minuto o cuento del tamaño de la palma de la mano" (Koch, 2004: 51).

\section{0. "La serialización es distinta de la continuación y es más probable en unos géneros que en otros"}

Frente a los textos unitarios y extensos que abanderaba la novela del XIX, el microrrelato tiende a la fragmentación. Esta predisposición genera varios tipos de vínculos entre microtextos de acuerdo con los niveles de este que se vean involucrados. Por ejemplo, las categorías establecidas por Lauro Zavala, fragmentos, detalles y fractales, según los nexos resultantes de las estrategias de serialidad:

La relación entre el todo y las partes hoy en día está determinada por las estrategias de la lectura, especialmente en el terreno de la narrativa literaria. Hay al menos seis géneros específicos de la serialidad narrativa: cuentos integrados, novela fragmentaria, minificciones integradas, ciclos de minificción, bestiarios fantásticos y cuentos dispersos. Las estrategias de serialidad son variaciones literarias de fragmentos, detalles y fractales. (2014: 37-38)

\section{1. "Hay géneros ocultos, subyacentes, susceptibles de confundirse como parte de otros géneros"}

Ya hemos adelantado que el microrrelato funda relaciones de diversa índole con otros géneros literarios, retroalimentándose e intercambiando sus rasgos primigenios. El estudio sistemático de la 
poligénesis de la escritura brevísima, abarca alrededor de cincuenta subgéneros de escritura mínima, descritos por el profesor mexicano Lauro Zavala:

A. Versiones mínimas de géneros canónicos: minicuento (clásico), microrrelato (moderno), microensayo, minicrónica, artículo (entre opinión y testimonio), miniteatro (no más de 3 minutos sobre escena), fábula (alegoría moralizante), metaficción ultracorta, narrativa infantil mínima, narrativa alética mínima (fantasía y terror), narrativa policiaca mínima (cuyo enigma es simultáneamente epistémico, axiológico y deóntico).

B. Géneros artísticos de extensión mínima (en la frontera con la narrativa literaria): poema en prosa, epigrama, soneto, canción, ecfrasis, haiku, lipograma y los juegos literarios propuestos por el colectivo OuLiPo (liponimia, perverbio, teatro alfabético, pangrama, tautograma...).

C. Géneros no artísticos de extensión mínima: definición, instructivo, confesión, anuncio oracular, grafitti, aforismo, wellerismo, acertijo, parábola, palíndromo, colmo, autorretrato, solapa, reseña, subtexto, adivinanza, mito

D. Series textuales: fractales (minificciones integradas en forma de cuento o novela), bestiarios (alegóricos), hipertextos (interactivos).

E. Subgéneros de la minificción: greguería (a partir de Gómez de la Serna), mitología (a partir de Roland Barthes), periquete (a partir de Arturo Suárez), canutero (periquete de literatura).

\section{2. "Un género puede estar íntimamente ligado a la independencia de una nación"}

Para comprender esta idea debemos remontarnos a los textos épicos que narraban las hazañas de los héroes encargados de defender la libertad de su país frente a invasiones extranjeras, asunto que contempla fundamentalmente la mitología clásica. "Los géneros de la épica se benefician de dos de los impulsos básicos de la humanidad: el anhelo de acción y el anhelo de trasformación" (Vital, 2012:75). La acción es inherente al género heroico, mientras que, la transformación, se producirá gracias al uso de la intertextualidad identificada y representada en los motivos de leyendas y mitos heredados. De este modo,

[...] el relato surge de la voluntad relatoria de esa entidad que encripta la narración en unas pocas palabras, y organiza una red de sentido más allá de ellas, por medio de señales inscriptas en el intratexto, el intertexto y el extratexto, que van en busca de un lector que complete su sentido. [...] Este efecto de indecisión que opera en el momento de la lectura es uno de los núcleos más eficaces en la producción de sentido de los microrrelatos. (Pollastri, 2008: 167)

Las grandes epopeyas grecolatinas se convierten en hipotexto de microrrelatos intertextuales en los que reconoceremos a personajes míticos como: Caronte, el barquero de la laguna Estigia; Heracles, el héroe griego por excelencia; Andrómeda o a un perseverante Ulises tratando de volver a Ítaca para encontrarse con su amada Penélope:

\section{LA VUELTA A CASA}

El director suele llevar a los visitantes distinguidos al pabellón de los condenados a cadena perpetua, para que escuchen a este hombre contar la historia de su crimen: Mucho tiempo lejos de casa, primero en la otra punta del planeta, días y días de reuniones para intentar entrar en la dichosa fusión, y cuando conseguimos eliminar las resistencias y vencer a nuestros adversarios tuve que recorrer una por una las sucursales, las filiales, las empresas asociadas, evitando todas las asechanzas, unos querían hechizarme con malas mañas, otros pretendían que me quedase, zafándome de los cantos seductores, de quienes me devorarían di pudiesen de los que quisieran destruirme. Yo estaba a punto de explotar. Llego por fin a casa, de improviso, y me encuentro con que mi mujer ha organizado una fiesta. Al parecer, lleva montando estas juergas casi desde que me fui, mi casa llena de gorrones bebiéndose mis vinos, comiéndose mis cecinas y mis quesos. Y mi mujer me dice, tan tranquila, que mi hijo se ha marchado por ahí, no sabe a dónde. Subo 
a mi estudio y me encuentro con que han instalado allí una especie de telar enorme; todo está revuelto, hilos, varillas de madera, tijeras. Exploté, agarré un par de escopetas, una pistola; bajé a la sala y empecé a disparar; estaba tan ciego de ira que también me la llevé a ella por delante. El director no se cansa de escuchar este relato, menuda odisea, exclama una vez más, mientras se aleja por el corredor con los visitantes. José M. ' José Merino, La glorieta de los fugitivos, pp.66-67.

\section{3. "Hay géneros de la acción y géneros de la introspección"}

La presunción anterior aludía a la consustancialidad entre la acción y el género épico que atañe a la colectividad cultural de un pueblo. El descreimiento en los nuevos circuitos culturales, en la tecnología y en los medios de comunicación de masas vinculados a la "cultura del reciclaje", ha desembocado en la banalización del género, fruto del desconocimiento de sus rasgos discursivos, formales, temáticos y pragmáticos que a su vez favorecen el carácter proteico del microrrelato:

Texto narrativo muy breve, destinado a ser leído en forma autónoma, o sea, sin nexos aparentes con textos previos o subsiguientes; si aparece conectado con otros de iguales características, forma el conjunto que se conoce como microrrelatos integrados o ficción integrada [...] manifiesta con frecuencia una actitud experimental frente al lenguaje y porque apela a la intertextualidad, la reescritura de temas clásicos o la parodia de los mismos, una visión no convencional del mundo y, en términos generales, una actitud desacralizadota de la institución literaria tradicional. (Lagmánovich, 2006: 63)

\section{4. "La distribución de productos literarios $y$, en general, las condiciones del mercado son un factor en la expansión o contracción de un género; ese factor es superable"}

Las prolijas antologías responden a la demanda de un nuevo público lector. Así las ediciones de: Antonio Fernández Ferrer, La mano de la hormiga. Los cuentos más breves del mundo y de las literaturas hispánicas, (1990); la de José Luís González, Dos veces cuento. Antología de microrrelatos (1998); la de Lauro Zavala, Relatos vertiginosos. Antología de cuentos anónimos, (2000); la de Miguel Díez R., Antología de cuentos e historias mínimas (2002); la de Clara Obligado, Por favor, sea breve, (2001); la de David Lagmanovich, La otra mirada. Antología Del Microrrelato Hispánico (2005) o la de Neus Rotger, Los microrrelatos de Quimera (2005), cubren las necesidades de ese creciente modelo de nuevo lector.

Además, gracias a la canonización y reconocimiento académico del género proliferan los congresos y simposios a nivel nacional e internacional, cuyo objetivo es consolidar al microrrelato, o a la microficción como el género o el subgénero literario o modalidad narrativa más representativo de la posmodernidad.

\section{5. "La hipótesis puede ser un género"}

El privilegiado estatus del microrrelato contemporáneo es fruto de un proceso evolutivo que parte de los denominados precursores de la brevedad, ubicados entre finales del XIX y el primer tercio del siglo XX, época en la que el Modernismo español abría paso a las Vanguardias históricas: 


\begin{abstract}
Hasta hace poco estas formas breves no se tomaban en serio y se consideraban cualquier cosa menos literatura. Por otro lado, no hay que olvidar que, desde siempre, la literatura primero se escribe y luego se examina y se estudia. En el caso del microrrelato ha ocurrido una cosa curiosa en torno a su estudio: la crítica apenas se ha ocupado de él, sin embargo, los propios autores han teorizado sobre el tema, cosa que no suele ocurrir con el resto de los géneros. (Navarro Romero, 2008: 470)
\end{abstract}

Buen ejemplo de la casuística mencionada por Navarro Romero es el autor José $\mathrm{M}^{\mathrm{a}}$ Merino, cuyo corpus de microrrelatos pertenece a esta tesis, y quien ha elaborado numerosos textos que tratan de definir sus rasgos fundacionales y, por ende, al género en sí mismo:

\title{
UNA MORDEDURA
}

Investigaba las especies del Jardín Literario: los ecos del cenador de los monólogos lo ensordecían, el rincón de las elegías le producía algo de alergia, solía ortigarse en la glorita de los sonetos, en el sendero de la poesía de la experiencia daba demasiado el sol, a veces le sofocaba el intenso aroma de las novelas totales, le aburrían cósmicamente los best-sellers. Solía descansar en uno de los prados que rodean la Glorieta Miniatura, entre los relatos brevísimos, pero un día se quedó dormido y un minicuento carnívoro le mordió un brazo. La mordedura se infectó, y quedó manco. Así fue como se le ocurrió escribir el Quijote más breve del mundo.

José M. ${ }^{a}$ José Merino, La glorieta de los fugitivos, p.219.

A modo síntesis, de acuerdo con las premisas establecidas por Paul Ricoeur en Teoría de la interpretación (1976), concluiremos que, el microrrelato goza de sus propias marcas de género tanto formales (trama, personajes, espacio, tiempo-elipsis, diálogos, final sorpresivo y enigmático, valor del título y experimentación lingüística) como temáticas (intertextualidad, metaficción, ironía, parodia, humor e intención crítica); posee una intención o función específica, la de subvertir las normas preestablecidas e incitar mediante esta ruptura a la reflexión y el análisis; exige un lector concreto, activo y competente capacitado para sellar el pacto de lectura; utiliza para su difusión diversos medios y soportes, y la práctica, tanto de su escritura como de su lectura, está ligada a la condición natural de narrar del hombre.

\section{Referencias bibliográficas}

BUSTAMANTE, L. Del relato mínimo a la narración aumentada: algunos ejemplos en el microrrelato español actual. Microtextualidades. Revista Internacional de microrrelato y minificción (1), 2643.

CALINESCU, M. (2003). Cinco caras de la modernidad. Madrid: Alianza.

ESTÉBANEZ CALDERÓN, D. (1999). Diccionario de términos literarios. Madrid: Alianza.

GARRIDO DOMÍNGUEZ, A. (2008). El microcuento y la estética posmoderna. En S. Montesa. (Ed.), Narrativas de la posmodernidad del cuento al microrrelato (pp.49-66). Málaga: AEDILE

KOCH, D. (2004). ¿Microrrelato o minicuento? ¿Minificción o hiperbreve?”. En F. Noguerol (Ed.), Escritos disconformes: nuevos modelos de lectura (pp. 45-54). Salamanca: Ediciones Universidad de Salamanca. 
LAGMANOVICH, D. (2009). El microrrelato hispánico: algunas reiteraciones. Iberoamericana, IX, (36), 85-96. Recuperado de http://www.iai.spk-berlin.de/fileadmin/dokumentenbibliothek/ Iberoamericana/36-2009/36_Lagmanovich.pdf

LAGMANOVICH, D. (2006). El microrrelato. Teoría e historia. Palencia: Menoscuarto.

MERINO, J. M. (2007). La glorieta de los fugitivos. Madrid, Páginas de Espuma.

NAVARRO ROMERO, R. M. (2009). El microrrelato: género literario del siglo XXI. En S. Montesa. (Ed.), Narrativas de la posmodernidad del cuento al microrrelato (pp.443-456). Málaga: AEDILE.

NOGUEROL JIMÉNEZ, F. (1992). Sobre el micro-relato latinoamericano: cuando la brevedad noquea.... Lucanor: Revista del cuento literario, (8), 117-133

POLLASTRI, L. (2008). En I. Andrés-Suárez y A. Rivas (Eds.), La era de la brevedad. El microrrelato hispánico (pp. 159-182). Palencia: Menoscuarto.

POZUELO YVANCOS, J. M. ' (2005). Narrativa y Posmodernidad, Cuadernos de Mangana 30, Centro de Profesores y Recursos de Cuenca.

PUJANTE CASCALES, B. (2013). El microrrelato hispánico (1988-2008): teoría y análisis. Universidad de Murcia.

RICOEUR, P. (2006). Teoría de la interpretación. Discurso y excedente de sentido. Ciudad de México: Siglo XXI Editores. Recuperado de: http://mastor.cl/blog/wp-content/uploads/2015/08/Ricoeur.Teoria-de-la-interpretacion.-Siglo-XXI.pdf

VALLES CALATRABA, J. R. (2008). Teoría de la narrativa. Una perspectiva sistemática. Madrid: Iberoamericana-Verwert

VITAL, A. (2012). Quince hipótesis sobre géneros. Ciudad de México: Instituto de Investigaciones Filológicas.

ZAVALA, L. (2014). Minificción Contemporánea. La Ficción Ultracorta y la Literatura Posmoderna. Guanajuato: Universidad de Guanajuato.

ZAVALA, L. (2005). La minificción bajo el microscopio. Bogotá: Universidad Pedagógica Nacional. 